\title{
PET of Serotonin 1A Receptors and Cerebral Glucose Metabolism for Temporal Lobectomy
}

\author{
William H. Theodore ${ }^{1}$, Ashley R. Martinez ${ }^{1}$, Omar I. Khan ${ }^{1}$, Clarissa J. Liew ${ }^{1}$, Sungyoung Auh ${ }^{2}$, Irene M. Dustin ${ }^{1}$, \\ John Heiss ${ }^{3}$, and Susumu Sato ${ }^{4}$

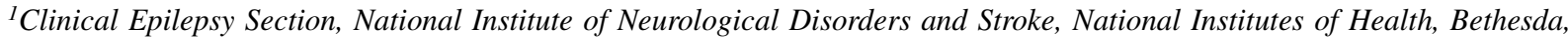 \\ Maryland; ${ }^{2}$ Office of the Clinical Director, National Institute of Neurological Disorders and Stroke, National Institutes of Health, \\ Bethesda, Maryland; ${ }^{3}$ Surgical Neurology Branch, National Institute of Neurological Disorders and Stroke, National Institutes of \\ Health, Bethesda, Maryland; and ${ }^{4}$ EEG Section, National Institute of Neurological Disorders and Stroke, National Institutes of \\ Health, Bethesda, Maryland
}

The objective of this study was to compare 5-hydroxytryptamine receptor $1 \mathrm{~A}\left(5-\mathrm{HT}_{1 \mathrm{~A}}\right)$ PET with cerebral metabolic rate of glucose (CMRglc) PET for temporal lobectomy planning. Methods: We estimated $5-\mathrm{HT}_{1 \mathrm{~A}}$ receptor binding preoperatively with ${ }^{18} \mathrm{~F}-$ trans-4-fluoro- $N$-2-[4-(2-methoxyphenyl) piperazin-1-yl] ethyl- $N$ (2-pyridyl) cyclohexane carboxamide (18F-FCWAY) PET and CMRglc measurement with ${ }^{18} \mathrm{~F}-\mathrm{FDG}$ in regions drawn on coregistered MRI after partial-volume correction in 41 patients who had anterior temporal lobectomy with at least a 1-y follow-up. Surgery was tailored to individual preresection evaluations and intraoperative electrocorticography. Mean regional asymmetry values and the number of regions with asymmetry exceeding 2 SDs in 16 healthy volunteers were compared between seizure-free and non-seizure-free patients. ${ }^{18} \mathrm{~F}-\mathrm{FCWAY}$ but not ${ }^{18} \mathrm{~F}-\mathrm{FDG}$ and MRI data were masked for surgical decisions and outcome assessment. Results: Twenty-six of 41 (63\%) patients seizure-free since surgery had significantly different mesial temporal asymmetries, compared with 15 non-seizure-free patients for both ${ }^{18} \mathrm{~F}-\mathrm{FCWAY}$ $\left(\mathrm{F}_{1,39}=5.87 ; P=0.02\right)$ and ${ }^{18} \mathrm{~F}-\mathrm{FDG}$ PET $\left(\mathrm{F}_{1,38}=5.79 ; P=\right.$ $0.021)$. The probability of being seizure-free was explained by both ${ }^{18} \mathrm{~F}-\mathrm{FDG}$ and ${ }^{18} \mathrm{~F}-\mathrm{FCWAY} \mathrm{PET}$, but not MRI, with a significant additional ${ }^{18} \mathrm{~F}-\mathrm{FCWAY}$ effect $\left(\chi_{2}^{2}=9.8796 ; P=0.0072\right)$ after the probability of being seizure-free was explained by ${ }^{18} \mathrm{~F}-\mathrm{FDG}$. Although MRI alone was not predictive, any combination of 2 lateralizing imaging studies was highly predictive of seizure freedom. Conclusion: Our study provides class III evidence that both 5- $\mathrm{HT}_{1 \mathrm{~A}}$ receptor PET and CMRglc PET can contribute to temporal lobectomy planning. Additional studies should explore the potential for temporal lobectomy based on interictal electroencephalography and minimally invasive imaging studies.

Key Words: glucose metabolism; positron emission tomography; serotonin receptors; temporal lobe epilepsy

J Nucl Med 2012; 53:1375-1382

DOI: 10.2967/jnumed.112.103093

\footnotetext{
Received Jan. 12, 2012; revision accepted Apr. 4, 2012.

For correspondence contact: William H. Theodore, Clinical Epilepsy Section, National Institute of Neurological Disorders and Stroke, National Institutes of Health, Building 10, Room 7D-43, Bethesda, MD 20892.

E-mail: theodorw@ninds.nih.gov

Published online Jul. 10, 2012.

COPYRIGHT @ 2012 by the Society of Nuclear Medicine and Molecular Imaging, Inc.
}

A lthough it is the most successful treatment for intractable temporal lobe epilepsy (TLE), surgery stops seizures that impair consciousness in only about $60 \%$ of patients (1). Several factors show a significant association with good surgical outcome, but the ability to predict seizure freedom after temporal lobectomy is limited (2). Moreover, the cost of current evaluation, based on inpatient ictal video-electroencephalography (video-EEG), is high and exposes patients to the risk of generalized tonic-clonic seizures induced by antiepileptic drug withdrawal.

${ }^{18}$ F-FDG PET has become an accepted part of temporal lobectomy evaluation. However, the role of functional imaging studies for seizure focus localization, particularly at a time of continuing refinement of MRI and increasing concerns about the cost of medical care, remains uncertain $(3,4)$. There are only limited data on the value of specific neuroreceptor ligands. Moreover, methods for application of PET results in individual cases vary among investigators. Few previous studies have attempted to examine the value to presurgical evaluation of performing PET with a receptor ligand in addition to ${ }^{18} \mathrm{~F}-\mathrm{FDG}$.

Studies using several PET ligands for the 5-hydroxytryptamine receptor $1 \mathrm{~A}\left(5-\mathrm{HT}_{1 \mathrm{~A}}\right)$ have found reduced binding in patients with TLE in mesial temporal structures ipsilateral to the epileptic focus and in additional regions including the insula and anterior cingulate (5-9). Reduced $5-\mathrm{HT}_{1 \mathrm{~A}}$ receptor binding may be related to increased limbic excitability in patients with TLE and in animal models $(10,11)$.

To test the hypothesis that PET with the highly selective $5-\mathrm{HT}_{1 \mathrm{~A}}$ receptor antagonist ${ }^{18} \mathrm{~F}$-trans-4-fluoro- $\mathrm{N}-2-[4-(2-$ methoxyphenyl) piperazin-1-yl]ethyl- $N$-(2-pyridyl) cyclohexane carboxamide ( ${ }^{18} \mathrm{~F}$-FCWAY) would have predictive value for outcome after temporal lobectomy, we performed ${ }^{18} \mathrm{~F}$-FCWAY PET in addition to ${ }^{18} \mathrm{~F}$-FDG PET and standard clinical MRI in a study including all patients who underwent ${ }^{18} \mathrm{~F}$-FCWAY PET followed by temporal lobectomy from 2000 from 2010. We additionally studied the incremental value of imaging procedures for temporal lobectomy 
outcome, using a model in which structural MRI was followed by ${ }^{18} \mathrm{~F}$-FDG and ${ }^{18} \mathrm{~F}$-FCWAY PET.

\section{MATERIALS AND METHODS}

We studied 41 patients (22 women, 19 men; mean age $\pm \mathrm{SD}$, $34.2 \pm 9.5 \mathrm{y})$ with medically refractory TLE, referred to the Clinical Epilepsy Section, National Institute of Neurologic Disorders and Stroke (NINDS), National Institutes of Health. Epilepsy duration was $25 \pm 12 \mathrm{y}$. Nine patients had been included in a previous study (12). All 41 patients underwent prolonged surface ictal video-EEG recording; 19 underwent additional subdural electrode recordings before temporal lobectomy. All patients had surgery, with a mean follow-up of $6.7 \pm 2.9 \mathrm{y}$ (range, $1-11 \mathrm{y}$ ). Surgery was based on the results of video-EEG monitoring, structural MRI, and other standard procedures such as neuropsychologic evaluation.

All patients underwent anterior temporal lobectomy, tailored to individual preresection evaluations and intraoperative electrocorticography. All resections included the temporal tip, a minimum of $1 \mathrm{~cm}$ of the anterior part of the superior temporal gyrus, and between 3 and $5 \mathrm{~cm}$ of the middle and inferior temporal gyri. Resection was extended to involve epileptogenic frontal regions identified on subdural electrode recording in 2 patients (Table 1). On postoperative evaluation, performed in the NINDS Clinical Epilepsy Section outpatient clinic, patients were classified as either free from seizures impairing consciousness (seizure-free) (1) or having persistent seizures (non-seizure-free).

Each patient underwent 1.5-T or 3-T MRI (Signa; GE Healthcare) for which fluid-attenuated inversion recovery, T1-weighted, and T2-weighted images were obtained. A 3-dimensional spoiledgradient-recalled or magnetization-prepared rapid-acquisition gradient echo volume study was obtained for PET coregistration. Neuroradiologists who were unaware of ictal electroencephalographic and PET data interpreted the MRI scans.

PET was performed on an Advance Tomograph (GE Healthcare). A 37-MBq (10-mCi) dose of ${ }^{18}$ F-FCWAY was injected over $60 \mathrm{~s}$, and dynamic frames (1-5 min) were acquired in 3-dimensional mode for $120 \mathrm{~min}$. Thirty radial arterial blood samples were taken to quantify ${ }^{18} \mathrm{~F}$-FCWAY concentration, and selected samples were used to measure ${ }^{18} \mathrm{~F}$-fluorocyclohexanecarboxylic acid. Brain tissue activity frames were corrected for brain acid metabolite and ${ }^{18} \mathrm{~F}$-fluorocyclohexanecarboxylic acid uptake, vascular radioactivity, and ${ }^{18} \mathrm{~F}$-fluoride metabolite spillover from the skull.

${ }^{18} \mathrm{~F}-\mathrm{FDG}$ PET was performed after injection of $185 \mathrm{MBq}(5$ $\mathrm{mCi})$ of ${ }^{18}$ F-FDG.

For PET data analysis, ${ }^{18} \mathrm{~F}-\mathrm{FCWAY}$ V/f1 (where V is receptor volume of distribution and $\mathrm{f} 1$ is ${ }^{18} \mathrm{~F}$-FCWAY plasma-free fraction) and cerebral metabolic rate of glucose (CMRglc) parametric images were coregistered to MR images and had partial-volume correction performed using an algorithm that produces voxel-byvoxel binary gray matter, white matter, and cerebrospinal fluid masks $(8,12)$. We used V/f1 as our binding index to avoid issues related to choosing a region to represent nonspecific binding $(8,12)$. Anatomic regions of interest (ROIs) were drawn on coregistered MR images.

No patient had experienced seizures for at least $2 \mathrm{~d}$ before PET studies, and all patients were observed carefully during scans to exclude ictal activity. One patient did not undergo ${ }^{18} \mathrm{~F}$-FDG PET. ${ }^{18} \mathrm{~F}-\mathrm{FCWAY}$ but not ${ }^{18} \mathrm{~F}-\mathrm{FDG}$ and MRI data were masked for surgical decisions and outcome assessment.
For the primary analysis, we calculated ROI asymmetry indices (AI) using the formula (right - left)/(0.5) (right + left). To facilitate comparison across patients, AI was multiplied by $(-1)$ for patients with right-sided foci. A linear mixed model was used to examine the difference in AI between seizure-free and non-seizure-free outcomes using 4 ROIs (hippocampus, amygdala, parahippocampal gyrus, and fusiform gyrus by taking into account correlation among the 4 measurements, using a compound symmetric covariance structure).

Because no significant interaction between group (seizure-free and not seizure-free) and region was found for either ${ }^{18} \mathrm{~F}-\mathrm{FCWAY}$ or ${ }^{18} \mathrm{~F}-\mathrm{FDG}$, a final linear mixed model analysis with group and region as main factors was performed for ${ }^{18} \mathrm{~F}-\mathrm{FCWAY}$ and ${ }^{18} \mathrm{~F}-$ FDG PET, respectively. Post hoc comparisons of mean AI between seizure-free and non-seizure-free patients were performed for the hippocampus, amygdala, parahippocampal, and fusiform gyri.

In addition, we examined individual scans for regions with AI greater than 2 SDs above control values. To determine limits to the AI in healthy volunteers, we used data from previous studies (12). For this analysis, we examined both mesial temporal and additional neocortical regions-including frontal and parietal cortex; insula; and inferior, mid, and superior temporal lobes-because previous studies have suggested that ${ }^{18} \mathrm{~F}$-FDG PET provides better lateralizing than localizing data, and ${ }^{18} \mathrm{~F}$-FCWAY detected neocortical binding reductions in TLE $(3,4,8)$.

Student $t$ tests were used to compare the effects of surgery outcome and the presence of an abnormality on MRI or ${ }^{18} \mathrm{~F}$ FCWAY binding and ${ }^{18} \mathrm{~F}$-FDG PET CMRglc regional AI. For the secondary analysis, Student $t$ tests were used to test the relation of the number of regions with reduced 5- $\mathrm{HT}_{1 \mathrm{~A}}$ binding or CMRglc on surgery outcome. Subsequently, the $\chi^{2}$ test was used to compare clinical scan classification with surgical outcome.

The probability of being seizure-free was modeled on the clinical scan classification using a stepwise logistic regression with 3 categoric covariates: MRI, ${ }^{18} \mathrm{~F}-\mathrm{FCWAY}$ PET, and ${ }^{18} \mathrm{~F}-\mathrm{FDG}$ PET.

SPSS (version 19; IBM Inc.) was used for performing Student $t$ tests and $\chi^{2}$ tests. Linear mixed model and stepwise logistic regression were performed using SAS (version 9.1.3; SAS Institute). All tests were 2 -sided, and a significance level of 0.05 was used unless indicated otherwise.

The study was approved by the National Institutes of Health Combined Neurosciences Institutional Review Board and the Radiation Safety Committee, under 45 U.S. Code of Federal Regulations, part 46.

\section{RESULTS}

Twenty-six of $41(63 \%)$ patients had been seizure-free since surgery (Table 1). Eight of 15 patients with normal MRI results, compared with 18 of 26 without, became seizure-free. This difference was not significant. Seventeen patients underwent invasive electroencephalographic studies with subdural electrodes, performed for functional mapping and seizure focus localization; there was no clear relation of invasive studies to surgical outcome.

After surgery, patients were followed for $4.0 \pm 2.6 \mathrm{y}$ (mean $\pm \mathrm{SD}$ ). There was no difference between seizure- 


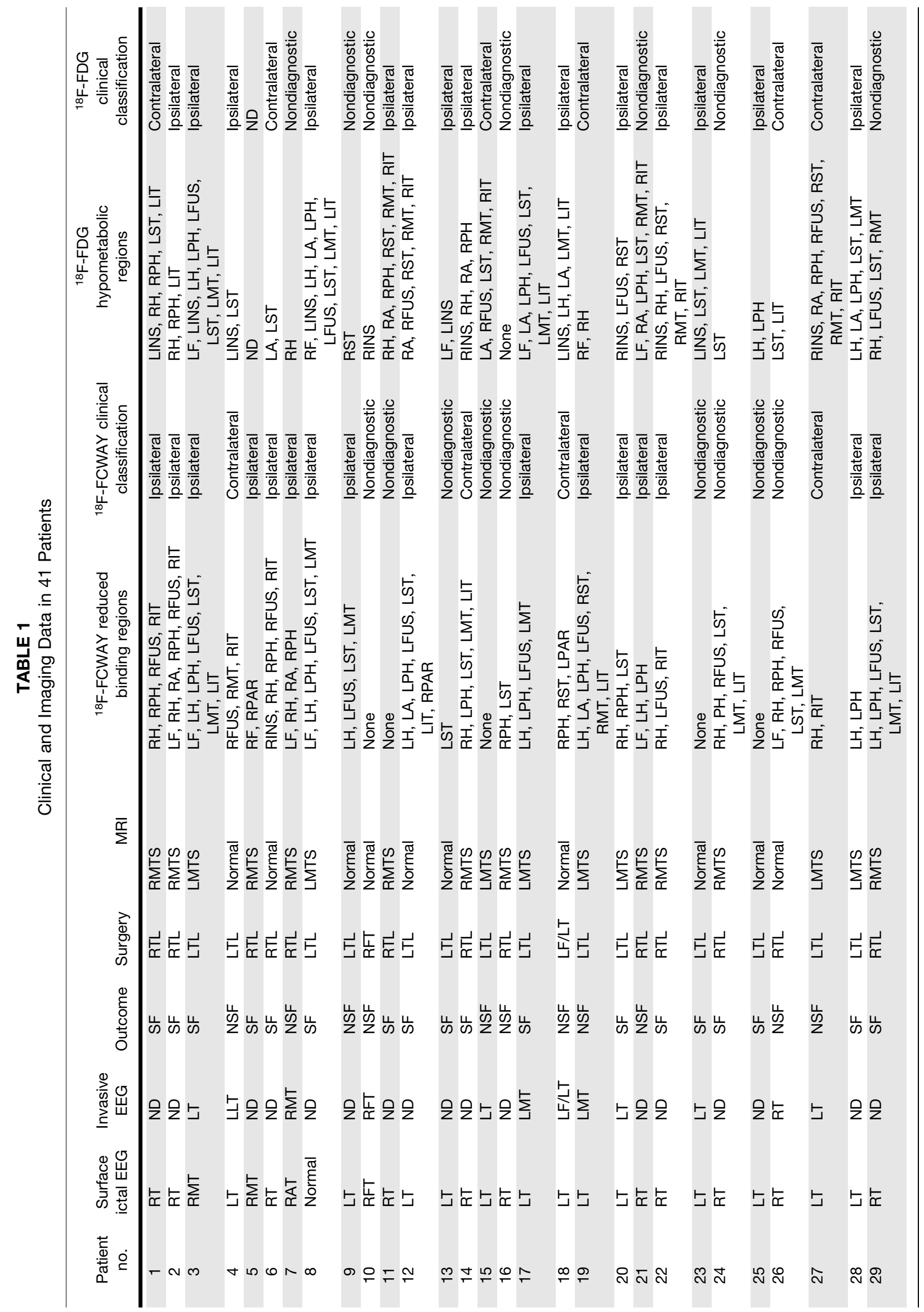




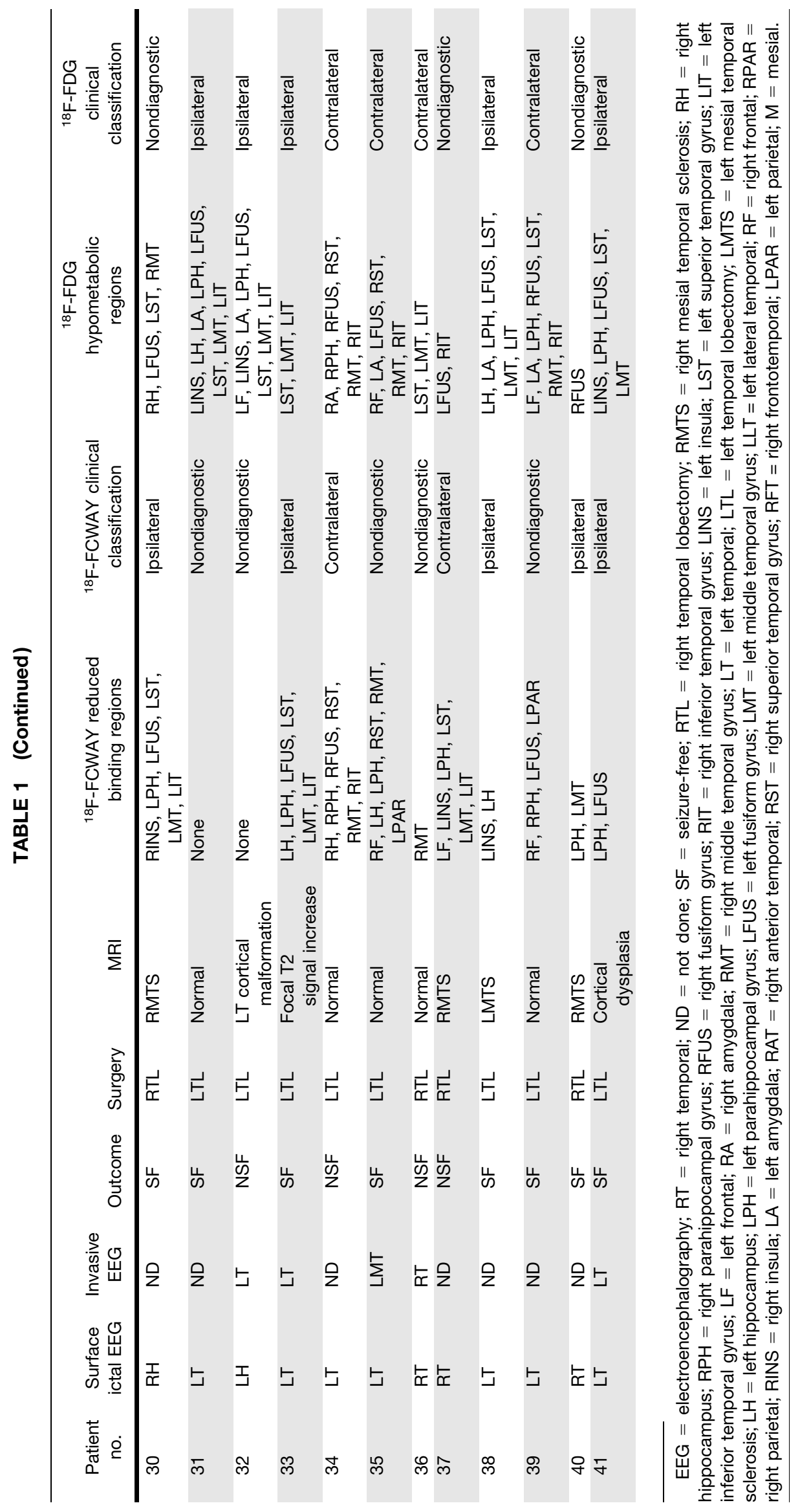

1378 The Journal of Nuclear Medicine • Vol. 53 • No. 9 • September 2012 
free $(4.0 \pm 2.5 \mathrm{y})$ and non-seizure-free $(4.2 \pm 2.9 \mathrm{y})$ patients.

\section{F-FCWAY PET}

There were significant mean AI differences between seizure-free and non-seizure-free patients for ${ }^{18} \mathrm{~F}$-FCWAY $\left(\mathrm{F}_{1,39}=5.87 ; P=0.02\right)$.

On post hoc regional comparisons, seizure-free patients had significantly lower group mean ${ }^{18} \mathrm{~F}$-FCWAY-PET $5-\mathrm{HT}_{1 \mathrm{~A}}$ binding in the hippocampus, amygdala, and parahippocampal gyrus (Table 2). After Bonferroni adjustment for multiple comparisons, using a threshold of 0.0125 , the amygdala remained significant. Mann-Whitney $U$ tests led to comparable results $(P=0.01$ for the amygdala and 0.07 for the hippocampus).

Patients who became seizure-free had significantly more regions with reduced binding ipsilateral to the resection when both mesial and lateral regions were included $(2.9 \pm$ 2.2 vs. $1.3 \pm 1.7 ; P<0.02$ ). Only a trend was present for mesial regions alone.

\section{${ }^{18}$ F-FDG PET}

Seizure-free patients had higher ${ }^{18} \mathrm{~F}$-FDG PET AI $\left(\mathrm{F}_{1,38}=\right.$ 5.79; $P=0.021) .{ }^{18} \mathrm{~F}-\mathrm{FDG}$ PET CMRglc was reduced in the hippocampus and fusiform gyrus, although no region remained significant after Bonferroni adjustment (Table 3). On Mann-Whitney $U$ testing, the hippocampus was significant at $P<0.05$. There were significantly more individual hypometabolic regions $(3.8 \pm 2.4$ vs. $1.5 \pm 2.3 ; P<0.01)$. There were no significant differences in AI between patients with normal and abnormal MRI.

After the primary analysis, we tested the relation of insular $5-\mathrm{HT}_{1 \mathrm{~A}}$ binding and CMRglc to outcome. There was no difference in AI between seizure-free and not seizure-free patients for either parameter.

\section{Electroencephalographic Data}

Surface ictal electroencephalography and subdural recording results (Table 1) were used to plan surgery and thus were not independent factors in predicting PET results or surgical outcome. There was no relation between surgical outcome and the number of seizures recorded during videoEEG monitoring $(4.3 \pm 2.1$ vs. $4.4 \pm 2.6)$. Interictal electroencephalography recording results varied from tracing to tracing. Patients with consistent interictal discharges were not more likely to have ${ }^{18} \mathrm{~F}-\mathrm{FDG}$ PET hypometabolism or reduced $5-\mathrm{HT}_{1 \mathrm{~A}}$ binding but tended to be more likely to become seizure-free $(0.05<P<0.10)$.

\section{Clinical Classification}

To classify individual PET scans clinically, we considered that-on the basis of the relation of the number of mesial temporal and neocortical regions with reduced $5-\mathrm{HT}_{1 \mathrm{~A}}$ binding or CMRglc to surgical outcome-patients with at least 2 low regions ipsilateral to the resection and more low ipsilateral than contralateral regions had ipsilateral findings. Scans with at least 2 contralateral abnormal regions, and more contralateral than ipsilateral regions, were classed as showing contralateral findings, and those not meeting either criterion were classed as nondiagnostic (Table 1). For both ${ }^{18}$ F-FCWAY and ${ }^{18}$ F-FDG PET, there was a significant relation between the clinical scan classification and surgery outcome. Sixteen of 20 patients with ipsilateral 5- $\mathrm{HT}_{1 \mathrm{~A}}$ receptor binding reduction, 1 of 6 with contralateral reduction, and 6 of 15 with nondiagnostic ${ }^{18} \mathrm{~F}$ FCWAY PET scans were seizure-free $\left(\chi^{2}=8.1 ; P<0.02\right)$. When clinical classification was based on mesial regions alone, only a trend was found $\left(\chi^{2}=4.6 ; 0.05<P<\right.$ $0.010)$. For ${ }^{18} \mathrm{~F}$-FDG, 17 of 20 patients with ipsilateral, 4 of 10 with contralateral, and 4 of 10 with nondiagnostic scans were seizure-free $\left(\chi^{2}=8.6 ; P<0.02\right)$. The results were similar $\left(\chi^{2}=7.5 ; P<0.03\right)$ using mesial ${ }^{18} \mathrm{~F}-\mathrm{FDG}$ regions alone. The presence of bilateral regions with reduced $5-\mathrm{HT}_{1 \mathrm{~A}}$ binding or hypometabolism did not affect outcome as long as the overall findings were ipsilateral.

A stepwise variable selection in the logistic regression selected ${ }^{18} \mathrm{~F}$-FDG and ${ }^{18} \mathrm{~F}$-FCWAY PET, but not MRI, as predictive of surgery outcome. There was a significant additional ${ }^{18}$ F-FCWAY effect $\left(\chi_{2}^{2}=9.8796 ; P=0.0072\right)$ after the probability of being seizure-free was explained by ${ }^{18}$ F-FDG (Fig. 1). In addition, there was a significant ${ }^{18} \mathrm{~F}-\mathrm{FDG}\left(\chi_{2}^{2}=8.64 ; P=0.013\right)$ effect after the probability of being seizure-free was explained by ${ }^{18} \mathrm{~F}$-FCWAY PET.

Any combination of 2 imaging studies was highly predictive of seizure freedom. Twelve of 13 patients with abnormal MRI results and ipsilateral ${ }^{18} \mathrm{~F}$-FDG PET results, compared with 13 of 27 who did not meet this criterion, were seizure-free $(P<0.01$, Fisher exact test $)$. Fifteen of 18 patients with abnormal MRI results and ipsilateral ${ }^{18} \mathrm{~F}$ FCWAY PET results, compared with 11 of 23 who did not meet this criterion, were seizure-free $(P=0.02)$. All 11

TABLE 2

Absolute ${ }^{18} \mathrm{~F}-\mathrm{FCWAY} 5-\mathrm{HT}_{1 \mathrm{~A}}$ Receptor PET Asymmetry and Surgery Outcome

\begin{tabular}{|c|c|c|c|c|}
\hline \multirow[b]{2}{*}{ Region } & \multirow[b]{2}{*}{ Seizure-free $(n=26)$} & \multirow[b]{2}{*}{ Non-seizure-free $(n=15)$} & \multicolumn{2}{|c|}{ Significance } \\
\hline & & & $t$ test & $P$ \\
\hline Hippocampus & $0.37 \pm 0.28$ & $0.13 \pm 0.38$ & $t_{39}=-2.20$ & 0.034 \\
\hline Parahippocampal gyrus & $0.18 \pm 0.17$ & $0.06 \pm 0.20$ & $t_{38}=-2.13$ & 0.04 \\
\hline Fusiform gyrus & $0.20 \pm 0.31$ & $0.06 \pm 0.30$ & $t_{38}=-1.42$ & 0.16 \\
\hline Amygdala & $0.22 \pm 0.16$ & $0.04 \pm 0.24$ & $t_{38}=-2.80$ & 0.008 \\
\hline
\end{tabular}


TABLE 3

Absolute ${ }^{18}$ F-FDG CMRglc PET Asymmetry and Surgery Outcome

\begin{tabular}{lcrcr}
\hline & & & \multicolumn{2}{c}{ Significance } \\
\cline { 3 - 4 } Region & Seizure-free $(n=25)$ & Non-seizure-free $(n=15)$ & $t$ test & $t_{38}=-2.80$ \\
\hline Hippocampus & $0.13 \pm 0.19$ & $-0.02 \pm 0.17$ & 0.017 \\
Parahippocampal gyrus & $0.07 \pm 0.18$ & $0.00 \pm 0.15$ & $t_{38}=-1.85$ & 0.07 \\
Fusiform gyrus & $0.12 \pm 0.18$ & $-0.03 \pm 0.24$ & $t_{38}=-2.21$ & 0.03 \\
Amygdala & $0.08 \pm 0.17$ & $0.02 \pm 0.14$ & $t_{38}=-1.10$ & 0.28 \\
\hline
\end{tabular}

patients for whom both PET scans showed ipsilateral abnormalities became seizure-free, compared with 14 of 29 who did not $(P<0.003)$.

\section{DISCUSSION}

Our data suggest that ${ }^{18} \mathrm{~F}-\mathrm{FCWAY}$ and ${ }^{18} \mathrm{~F}$-FDG PET have similar value for predicting seizure freedom after temporal lobectomy. Because only ${ }^{18} \mathrm{~F}-\mathrm{FDG}$ PET data were used in surgical planning, ${ }^{18} \mathrm{~F}-\mathrm{FCWAY}$ results were not subject to selection bias. Moreover, a combination of nuclear medicine studies may improve prediction of surgical outcome and reduce the need for ictal video-EEG monitoring and subdural or depth electrode studies.

We used seizure-free as an outcome measure, because this result seems to be associated with the best prognosis for improved quality of life (13). Improvements in depression and anxiety (not measured in our study) also are more likely to occur in patients who become seizure-free (14).

Several previous studies have found that ${ }^{18} \mathrm{~F}-\mathrm{FDG}$ PET could predict successful epilepsy surgery. A metaanalysis of forty-six ${ }^{18}$ F-FDG PET papers published between 1992 and 2006 found that predictive value for good outcome, including patients in Engel class 2, was $86 \%$ overall (80\% in patients with a normal MRI finding and $72 \%$ in patients with nonlocalized findings on ictal scalp electroencephalography) (15). In a study of 110 patients, ${ }^{18} \mathrm{~F}-\mathrm{FDG}$ PET was most useful when MRI findings were normal or did not show unilateral temporal abnormalities or when MRI findings were inconsistent with ictal electroencephalography results or videotaped seizure semiology (16). ${ }^{18} \mathrm{~F}-$ FDG PET did not appear to add value in the localization of foci by ictal scalp electroencephalography and MRI. For patients with a negative MRI finding, ${ }^{18}$ F-FDG PET incongruent with electroencephalography lateralization had a sig- nificantly worse outcome (17). In a large study, ${ }^{18} \mathrm{~F}-\mathrm{FDG}$ PET was not only predictive of class I/II outcome but also cost-effective, particularly for patients with normal MRI findings (18). Resection of the area of ${ }^{18}$ F-FDG PET hypometabolism beyond the MRI lesion may improve temporal lobectomy outcome (19). In a study of 28 patients who underwent amygdalohippocampectomy, ${ }^{18}$ F-FDG PET was superior to visual or volumetric MRI in identifying seizure-free patients; a combination of visual MRI and PET was the best outcome predictor (20).

$5-\mathrm{HT}_{1 \mathrm{~A}}$ receptor PET has shown reduced binding predominantly ipsilateral, but also contralateral, to temporal lobe foci (5-9). Thirty-eight of 42 patients studied with ${ }^{18} \mathrm{~F}$-4-(20-methoxyphenyl)-1-[20-( $N$-2-pirydynyl)- $p$-fluorobenzamido]-ethyl-piperazine $\left({ }^{18} \mathrm{~F}-\mathrm{MPPF}\right)$ had regions of focal binding potential reduction (21). Twenty-four of 27 patients who had temporal lobectomy were seizure-free, particularly when $5-\mathrm{HT}_{1 \mathrm{~A}}$ binding decreases included the hippocampus, amygdala, and temporal pole, even when MRI was unrevealing (21). Because the region of decreased binding potential coincided with the epileptogenic zone in a minority of patients, the 5-HT ${ }_{1 \mathrm{~A}}$ PET scans had, as in our study, better lateralizing than localizing value. Thirty-two of 38 patients had ${ }^{18} \mathrm{~F}$-FDG hypometabolism in the epileptogenic temporal lobe.

We found a higher proportion of contralateral hypometabolism or reduced binding than reported in a study using another $5-\mathrm{HT}_{1 \mathrm{~A}}$ receptor ligand, ${ }^{18} \mathrm{~F}-\mathrm{MPPF}(21)$. Technical factors of our analysis, including partial-volume correction, could have played a role, and the ligands were different. However, only 7 patients in that study, compared with 15 in ours, had a normal MRI result. It is possible that our patient population had a higher proportion of bilateral epileptogenic regions. Our finding that the presence of ${ }^{18} \mathrm{~F}-\mathrm{FCWAY}$ binding reductions or ${ }^{18} \mathrm{~F}-\mathrm{FDG}$ hypometabolism contralat-

FIGURE 1. A 44-y-old patient with 9-y history of intractable seizures; surface electroencephalography revealed left temporal seizure onset. (A) Normal MRI result. (B) Normal ${ }^{18} \mathrm{~F}$-FDG PET result. (C) ${ }^{18} \mathrm{~F}$-FCWAY PET shows left temporal binding decrease.
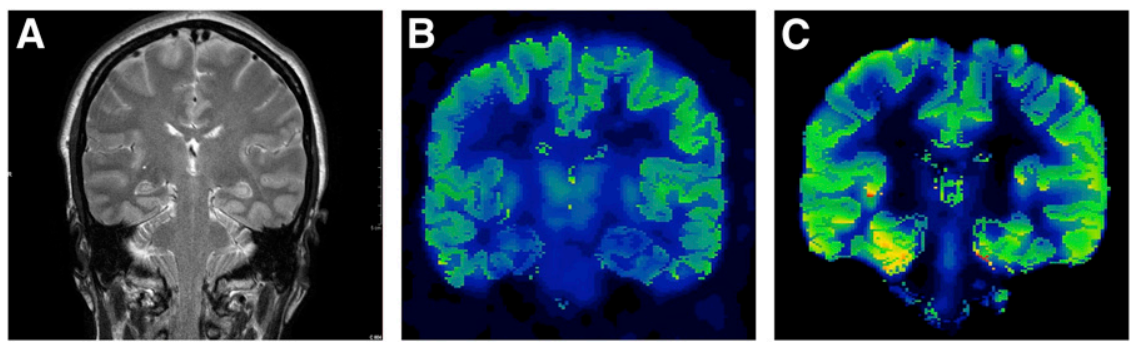
eral to the resection was associated with poor surgery outcome supports this possibility. ${ }^{18} \mathrm{~F}-\mathrm{FCWAY}$ may have localized mesial foci less specifically than ${ }^{18} \mathrm{~F}-\mathrm{MPPF}$ or, in our study, ${ }^{18} \mathrm{~F}$-FDG. If the 6 patients with contralateral ${ }^{18} \mathrm{~F}$ FCWAY results had been denied surgery, 5 would have been spared an ineffective operation whereas only 1 would have been deprived of a valuable procedure.

We found only a nonsignificant trend for patients with an abnormal MRI result to be more likely to be seizure-free. We did not perform quantitative MRI volumetry, which might have increased the predictive value of MRI. Most but not all studies suggest that an abnormal MRI result, particularly when congruent with ictal electroencephalography, improves surgical success in TLE $(22,23)$. In contrast, for patients who had stereoelectroencephalography, surgical outcome was similar for those with and without an abnormal MRI finding (24). Patients with MRI-negative TLE had more widespread ${ }^{18}$ F-FDG PET hypometabolism but similar surgical outcome and were thought to be more likely to have neocortical epileptogenic zones (25). Our results were similar in finding no difference in ${ }^{18} \mathrm{~F}-\mathrm{FDG}$ PET AI between patients with and without an abnormal MRI result. In a retrospective study, the chance of patients with a normal MRI finding being seizure-free (except for auras) after temporal lobectomy was $76 \%$ at 2 y and $69 \%$ at 7 y (26). In contrast, another group found that only $40 \%$ of MRI-negative patients were seizure-free after a mean follow-up of $5.8 \mathrm{y}$ (17).

Among other PET receptor ligands, only ${ }^{11} \mathrm{C}$-flumazenil has been studied for surgical evaluation. Ninety-four percent of TLE patients had reduced ${ }^{11} \mathrm{C}$-flumazenil binding, whereas $81 \%$ had abnormal MRI results and $89 \%$ had ${ }^{18} \mathrm{~F}-$ FDG PET hypometabolism (27). ${ }^{11} \mathrm{C}$-flumazenil PET provided information complementary to MRI and ${ }^{18} \mathrm{~F}$-FDG PET in delineating the site of seizure onset more precisely and showing bilateral binding reductions in patients with bitemporal epileptogenic zones. Both increased and decreased ${ }^{11} \mathrm{C}$-flumazenil binding was detected in patients with MRI-negative TLE, ipsilateral and contralateral to the presumed epileptogenic temporal lobe using SPM; hippocampal formation abnormalities were found in one third (28). The authors suggested that the increased binding of the temporal lobe white matter might represent potentially epileptogenetic microdysgenesis. In patients with mesial temporal sclerosis, those with increased ${ }^{11} \mathrm{C}$-flumazenil binding in periventricular white matter had a worse surgical outcome (29). Our finding that contralateral reduced ${ }^{18} \mathrm{~F}-\mathrm{FCWAY}$ binding predicted poor surgical outcome supports the role of PET receptor ligands in preoperative TLE evaluation.

Although visual analysis of PET images is common in clinical practice, quantitative methods including ROI-based $\mathrm{AI}$ measurement and statistical parametric mapping (SPM) may be more useful for predicting surgical outcome (25,30-33). In a small study, SPM was inferior to ROIbased AI for ${ }^{18} \mathrm{~F}$-FDG PET detection of an epileptogenic temporal lobe (34). For ${ }^{18} \mathrm{~F}-\mathrm{MPPF} 5-\mathrm{HT}_{1 \mathrm{~A}}$ receptor PET,
SPM had lower sensitivity than visual analysis for decreases in nondisplaceable binding potential in an epileptogenic temporal lobe but did show additional regions of increased or decreased binding of uncertain significance (21). A subsequent study found that AI measurement was superior to either SPM or visual analysis (35).

Our study was prospective and the main outcome of interest, ${ }^{18} \mathrm{~F}-\mathrm{FCWAY}$ PET detection of reduced $5-\mathrm{HT}_{1 \mathrm{~A}}$ receptor binding, was not available for presurgical clinical decision making and to the investigators who recorded postoperative outcome. Epilepsy imaging and surgical outcome studies experience limitations with regard to evidence classification. For example, it is no longer practical, or perhaps even ethical, to mask ${ }^{18}$ F-FDG PET or MRI data from neurologists making decisions on a recommendation for temporal lobectomy, and we did not do so. In our study, we followed the recommendations for essential elements for epilepsy imaging studies presented in a recent review (36).

\section{CONCLUSION}

The results of our study suggest that ${ }^{18} \mathrm{~F}-\mathrm{FCWAY}$ $5-\mathrm{HT}_{1 \mathrm{~A}}$ receptor imaging may be helpful in the presurgical evaluation for temporal lobectomy. Although we did not have enough patients with normal MRI results to draw definite conclusions, it seems reasonable to suggest that both ${ }^{18} \mathrm{~F}-\mathrm{FDG}$ and receptor PET will be most useful when MRI is nonrevealing. Additional studies should be designed to explore the circumstances under which patients could have epilepsy surgery based on interictal electroencephalography and a combination of minimally invasive imaging studies, without the risk and expense of ictal video-EEG monitoring.

\section{DISCLOSURE STATEMENT}

The costs of publication of this article were defrayed in part by the payment of page charges. Therefore, and solely to indicate this fact, this article is hereby marked "advertisement" in accordance with 18 USC section 1734.

\section{ACKNOWLEDGMENT}

The study was supported by the NINDS Division of Intramural Research. No other potential conflict of interest relevant to this article was reported.

\section{REFERENCES}

1. Wiebe S, Blume WT, Girvin JP, Eliasziw M. Effectiveness and Efficiency of Surgery for Temporal Lobe Epilepsy Study Group: a randomized, controlled trial of surgery for temporal-lobe epilepsy. N Engl J Med. 2001;345:311-318.

2. Uijl SG, Leijten FS, Arends JB, Parra J, van Huffelen AC, Moons KG. Prognosis after temporal lobe epilepsy surgery: the value of combining predictors. Epilepsia. 2008;49:1317-1323.

3. Duncan J. The current status of neuroimaging for epilepsy. Curr Opin Neurol. 2009;22:179-184.

4. Richardson M. Update on neuroimaging in epilepsy. Expert Rev Neurother. 2010;10:961-973. 
5. Toczek MT, Carson RE, Lang L, et al. PET imaging of 5-HT1A receptor binding in patients with temporal lobe epilepsy. Neurology. 2003;60:749-756.

6. Merlet I, Ostrowsky K, Costes N, et al. 5-HT1A receptor binding and intracerebral activity in temporal lobe epilepsy: an $\left[{ }^{18} \mathrm{~F}\right] \mathrm{MPPF}-\mathrm{PET}$ study. Brain. 2004;127:900-913.

7. Savic I, Lindstrom P, Gulyas B, et al. Limbic reductions of 5-HT1A receptor binding in human temporal lobe epilepsy. Neurology. 2004;62:1343-1351.

8. Giovacchini G, Toczek MT, Bonwetsch R, et al. 5-HT 1 a receptors are reduced in temporal lobe epilepsy after partial volume correction. J Nucl Med. 2005;46:1128-1135.

9. Assem-Hilger E, Lanzenberger R, Savli M, et al. Central serotonin 1A receptor binding in temporal lobe epilepsy: a [carbonyl-(11)C]WAY-100635 PET study. Epilepsy Behav. 2010;19:467-473.

10. Clinckers R, Smolders I, Meurs A, et al. Anticonvulsant action of hippocampal dopamine and serotonin is independently mediated by D and 5-HT receptors. J Neurochem. 2004;89:834-843.

11. Deng PY, Lei S. Serotonin increases GABA release in rat entorhinal cortex by inhibiting interneuron TASK-3 K+ channels. Mol Cell Neurosci. 2008;39:273-284.

12. Liew CJ, Lim Y-M, Bonwetsch R, et al. ${ }^{18} \mathrm{~F}$-FCWAY and ${ }^{18} \mathrm{~F}-\mathrm{FDG}$ PET in MRI negative temporal lobe epilepsy. Epilepsia. 2009;50:234-239.

13. Spencer SS, Berg AT, Vickrey BG, et al; Multicenter Study of Epilepsy Surgery. Health-related quality of life over time since resective epilepsy surgery. Ann Neurol. 2007;62:327-334.

14. Devinsky O, Barr WB, Vickrey BG, et al. Changes in depression and anxiety after resective surgery for epilepsy. Neurology. 2005;65:1744-1749.

15. Willmann O, Wennberg R, May T, Woermann FG, Pohlmann-Eden B. The contribution of ${ }^{18} \mathrm{~F}$-FDG PET in preoperative epilepsy surgery evaluation for patients with temporal lobe epilepsy: a meta-analysis. Seizure. 2007;16:509-520.

16. Uijl SG, Leijten FS, Arends JB, Parra J, van Huffelen AC, Moons KG. The added value of $\left[{ }^{18} \mathrm{~F}\right]$-fluoro-D-deoxyglucose positron emission tomography in screening for temporal lobe epilepsy surgery. Epilepsia. 2007;48:2121-2129.

17. Immonen A, Jutila L, Muraja-Murro A, et al. Long-term epilepsy surgery outcomes in patients with MRI-negative temporal lobe epilepsy. Epilepsia. 2010;51:2260-2269.

18. O'Brien TJ, Miles K, Ware R, Cook MJ, Binns DS, Hicks RJ. The cost-effective use of ${ }^{18} \mathrm{~F}$-FDG PET in the presurgical evaluation of medically refractory focal epilepsy. J Nucl Med. 2008;49:931-937.

19. Vinton AB, Carne R, Hicks RJ, et al. The extent of resection of FDG-PET hypometabolism relates to outcome of temporal lobectomy. Brain. 2007;130: $548-560$.

20. Boling WW, Lancaster M, Kraszpulski M, Palade A, Marano G, Puce A. Fluorodeoxyglucose-positron emission tomographic imaging for the diagnosis of mesial temporal lobe epilepsy. Neurosurgery. 2008;63:1130-1138.

21. Didelot A, Ryvlin P, Lothe A, Merlet I, Hammers A, Mauguiere F. PET imaging of brain 5-HT1A receptors in the preoperative evaluation of temporal lobe epilepsy. Brain. 2008;131:2751-2764.
22. McIntosh AM, Kalnins RM, Michell LA, et al. Temporal lobectomy: long-term seizure outcome, late recurrence and risks for seizure recurrence. Brain. 2004;127:2018-2030.

23. Bien CG, Szinay M, Wagner J, Clusmann H, Becker AJ, Urbach H. Characteristics and surgical outcomes of patients with refractory magnetic resonance imaging-negative epilepsies. Arch Neurol. 2009;66:1491-1499.

24. McGonigal A, Bartolomei F, Regis J, et al. Stereoelectroencephalography in presurgical assessment of MRI-negative epilepsy. Brain. 2007;130:3169-3183.

25. Carne RP, O'Brien TJ, Kilpatrick CJ, et al. MRI-negative PET-positive temporal lobe epilepsy: a distinct surgically remediable syndrome. Brain. 2004;127:2276-2285.

26. Fong JS, Jehi L, Najm I, Prayson RA, Busch R, Bingaman W. Seizure outcome and its predictors after temporal lobe epilepsy surgery in patients with normal MRI. Epilepsia. 2011;52:1393-1401.

27. Ryvlin P, Bouvard S, Le Bars D, et al. Clinical utility of flumazenil-PET versus $\left[{ }^{18} \mathrm{~F}\right]$ fluorodeoxyglucose-PET and MRI in refractory partial epilepsy: a prospective study in 100 patients. Brain. 1998;121:2067-2081.

28. Hammers A, Koepp MJ, Hurlemann R, et al. Abnormalities of grey and white matter $\left[{ }^{11} \mathrm{C}\right]$ flumazenil binding in temporal lobe epilepsy with normal MRI. Brain. 2002;125:2257-2271.

29. Hammers A, Koepp MJ, Brooks DJ, Duncan JS. Periventricular white matter flumazenil binding and postoperative outcome in hippocampal sclerosis. Epilepsia. 2005;46:944-948.

30. Theodore WH, Sato S, Kufta C, Balish MB, Bromfield EB, Leiderman DB. Temporal lobectomy for uncontrolled seizures: the role of positron emission tomography. Ann Neurol. 1992;32:789-794.

31. Manno EM, Sperling MR, Ding X, et al. Predictors of outcome after anterior temporal lobectomy: positron emission tomography. Neurology. 1994;44:23312336.

32. Wong CY, Geller EB, Chen EQ, et al. Outcome of temporal lobe epilepsy surgery predicted by statistical parametric PET imaging. J Nucl Med. 1996;37:10941100 .

33. Lin TW, de Aburto MA, Dahlbom M, et al. Predicting seizure-free status for temporal lobe epilepsy patients undergoing surgery: prognostic value of quantifying maximal metabolic asymmetry extending over a specified proportion of the temporal lobe. J Nucl Med. 2007;48:776-782.

34. Ohta Y, Nariai T, Ishii K, et al. Voxel- and ROI-based statistical analyses of PET parameters for guidance in the surgical treatment of intractable mesial temporal lobe epilepsy. Ann Nucl Med. 2008;22:495-503.

35. Didelot A, Mauguiere F, Redoute J, et al. Voxel-based analysis of asymmetry index maps increases the specificity of 18F-MPPF PET abnormalities for localizing the epileptogenic zone in temporal lobe epilepsies. J Nucl Med. 2010;51: 1732-1739.

36. Gaillard WD, Cross JH, Duncan JS, Stefan H, Theodore WH; Task Force on Practice Parameter Imaging Guidelines for International League Against Epilepsy, Commission for Diagnostics. Epilepsy imaging study guideline criteria: commentary on diagnostic testing study guidelines and practice parameters. Epilepsia. 2011;52:1750-1756. 